\title{
Effect of ultrasonic irradiation on rheological properties of asphaltenic crude oils
}

\author{
MOUSAVI Seyed Mohammadreza ${ }^{1,2}$, RAMAZANI Ahmad ${ }^{2 *}$, NAJAFI Iman ${ }^{1,2}$ \\ and DAVACHI Seyed Mohammad ${ }^{1}$
}

${ }^{1}$ Ultrasonic Research Group, Chemical and Petroleum Engineering Department, Sharif University of Technology, Azadi Ave., Tehran, Iran

${ }^{2}$ Chemical and Petroleum Engineering Department, Sharif University of Technology, Azadi Ave., Tehran, Iran

(C) China University of Petroleum (Beijing) and Springer-Verlag Berlin Heidelberg 2012

\begin{abstract}
In this work, the rheological changes of several crude oil samples exposed to ultrasonic waves for different time intervals in addition to the effect of temperature on viscosity behavior of heavy crude oils were investigated using a series of steady shear flow and oscillatory tests. The colloidal structural evolutions of flocs in oil samples were illustrated by analysis of the size distribution of flocculated asphaltene particles (confocal microscopy tests). The rheological investigations indicate that the ultrasonic irradiation dissolved heavy components in crude oil. After ultrasonic treatment, the Kouh-e-Mond crude oil was found to be pseudoplastic. In addition, confocal microscopy confirms that there was an optimum duration for ultrasonic irradiation, at which the viscosity and flocculation rate of asphaltenic crude oils reduced to the minimum values. The optimum was found to be approximately $40 \mathrm{~min}$ for the Kouh-e-Mond crude oil. Experimental results illustrate that the ultrasonic irradiation could disaggregate heavy colloid components in crude oil, and breakdown of asphaltene molecules would only occur in a specific time interval of irradiation. Also according to the temperature sweep test, the oil temperature rise caused by ultrasonic irradiation was not the main reason for rheological changes of the crude oil and this alteration may be due to physical and chemical phenomena induced by sonication in crude oil.
\end{abstract}

Key words: Asphaltene, ultrasonic technology, pseudoplastic property, viscoelastic property, yield stress, flocculation time

\section{Introduction}

Heavy oils are a dominant source of hydrocarbons, but the production of these crudes remains low, in particular because of their very high resistance to flow, which results from the high molecular weight and great percentage of heavy components such as asphaltene in heavy oils. Heavy oil does not flow well and needs a thermal or chemical activation. Although, flowing problems have been solved by these methods but other issues concerning surface facilities and transportation in long pipelines is still remaining as an unsolved challenge. Typical solutions such as dilution with a lighter oil or solvent are expensive and may not be economical (Argillier et al, 2001; Manan et al, 1997). Among many components of heavy crude oils, the asphaltene have been identified as the key in the crude oil viscosity. Challenges due to asphaltene deposition in production, transportation, and refinery operations are considered as one of the serious and complicated problems in the petroleum industry which puts lots of effort worldwide into prevention and remediation. Asphaltene precipitation also has negative

*Corresponding author. email: ramazani@sharif.edu

Received April 23, 2011 effects on absolute and relative permeability of reservoir rocks as deposited asphaltene may change the wettability of reservoir rocks from water wet to oil wet or block pore throats (Kamath et al, 1993; Minssieux, 1993; Pedroza and Calderon, 1995).

According to previous studies, self-association of these high molecular weight polar components does more or less severely depend on different parameters like temperature, pressure, and concentration. Nowadays, various methods are proposed and applied to remove asphaltene deposited in the wellbore and production facilities, ultrasonic technology is known as a potent method for reducing asphaltene flocculation rates by changing the kinetics of aggregation as well as for removing deposits (Garshol, 2005; Mousavi et al, 2010).

The study presented here aims to improve understanding of ultrasonic effects on crude oil rheology and evaluate this technology as a method of well bore stimulation. In these regards, rheological properties of heavy oils are examined as well as the size distribution of asphaltene flocs in various samples with different irradiation intervals.

Currently, according to our knowledge, only few investigations focus on the effects of ultrasonic waves on the rheological properties of the asphaltenic crude oil. In 
this paper, the effect of ultrasonic waves on breakdown of asphaltene flocs and high molecular components is experimentally investigated and the applicability of this technology to heavy oil production is also discussed.

\section{Materials and methods}

In this set of experiments ultrasonic waves were irradiated to oil samples by a generator with $45-\mathrm{kHz}$ frequency and $75-\mathrm{W}$ electrical output power designed by the Ultrasonic Research Group in Sharif University of Technology. The irradiation setup was bath type and the generator was in direct contact with the reaction mixture which in our case was crude oil. To calculate the value of energy exerted by the ultrasonic wave on the system, a set of calorimetry experiments was performed. The Kouh-e-Mond heavy crude oil was used as a raw material in all experiments. The oil properties are shown in Table 1. 200 milliliters of crude oil were placed in a $300-\mathrm{mL}$ beaker and exposed directly to ultrasonic waves for different time intervals of 5, 10, 15, 20, 30, 40, 50, 90, 120 and $240 \mathrm{~min}$. After ultrasonic treatment, the oil samples were cooled to ambient temperature of $26^{\circ} \mathrm{C}$ and prepared for following experimental studies.

Table 1 Crude oil properties (Azin et al, 2008)

\begin{tabular}{|c|c|}
\hline$P_{\text {sat }}$, psia & 624 \\
\hline Wax content, wt $\%$ & 2.40 \\
\hline Asphaltene content, wt $\%$ & 24.1 \\
\hline \multicolumn{2}{|l|}{ Composition, $\mathrm{mol} \%$} \\
\hline $\mathrm{N}_{2}$ & 0.66 \\
\hline $\mathrm{CO}_{2}$ & 0.23 \\
\hline $\mathrm{C}_{1}$ & 10.35 \\
\hline $\mathrm{C}_{2}$ & 2.35 \\
\hline $\mathrm{C}_{3}$ & 1.95 \\
\hline $\mathrm{C}_{4}-\mathrm{C}_{5}$ & 11.5 \\
\hline $\mathrm{C}_{6}-\mathrm{C}_{11}$ & 15.11 \\
\hline $\mathrm{C}_{12+}$ & 57.86 \\
\hline $\mathrm{MW} \mathrm{C}_{12+}$ & 485 \\
\hline Sp.Gr. $C_{12+}(60 / 60)$ & 1.0473 \\
\hline \multicolumn{2}{|l|}{ SARA tests, wt $\%$} \\
\hline Saturated & 21.83 \\
\hline Aromatic & 53.59 \\
\hline Resin & 9.58 \\
\hline Asphaltene & 14.70 \\
\hline
\end{tabular}

\subsection{Size distribution analysis}

To analyze the size distribution of asphaltene particles, $15 \mathrm{~mL}$ of $n$-pentane was added to $10 \mathrm{~mL}$ of $5 \%$ crude oil in toluene. This ratio of crude oil $/ n$-pentane ensures floc formation. At specified times of aggregation, three drops of the sample were taken to be observed in a confocal microscope. The samples were observed with a magnification of $500 \times$. The microscope was connected to a PC and images of the flocculated asphaltenes were stored in raw format of $640 \times 480$ pixels. Ten images were taken per sample to analyze the size as a function of flocculation time. Photoshop software was used to delineate the size of asphaltene flocs in different samples.

\subsection{Rheological investigation}

Rheological tests including steady shear, frequency sweep, oscillatory strain sweep and temperature sweep were done using a PAAR Physica MCR 301 rheometer operated by the Rheoplus software for Kouh-e-Mond crude before and after ultrasonic treatment. The measurements were carried out using plate-plate geometry with a diameter of $25 \mathrm{~mm}$. The measurement gap was set to $0.5 \mathrm{~mm}$ for all samples. To determine the linear viscoelastic region, oscillatory strain sweep measurements were performed from strain $0.01 \%$ to $100 \%$. The temperature sweep test was performed over a temperature range from 30 to $161^{\circ} \mathrm{C}$ at a constant frequency of $10 \mathrm{~Hz}$.

\section{Results and discussion}

\subsection{Calorimetry experiments}

At four different points in the irradiation bath the temperatures were measured and the average temperature changes were recorded at the total volume (Fig. 1). Experimental results show that the average temperature of $300 \mathrm{~mL}$ of $400 \mathrm{ppm} \mathrm{NaCl}$-water solution was raised from 28.8 to $34.7{ }^{\circ} \mathrm{C}$ (increased by $5.9^{\circ} \mathrm{C}$ ) in 1,050 seconds of ultrasonic irradiation. The total value of energy exerted on the system was calculated to be about $70.8 \mathrm{~W}$. The temperature increase is due to both passage of wave through saline water and also heat loss of the wave transducer in water.

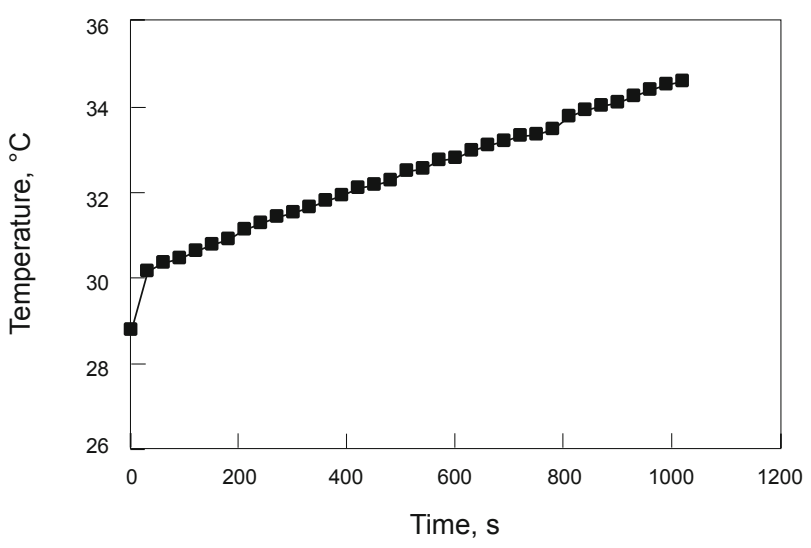

Fig. 1 Average temperature changes of $\mathrm{NaCl}$-water solution at different time intervals of irradiation

\subsection{Steady shear analysis}

Steady shear experiments were performed to investigate the ability of a fluid system to resist structural changes during 
simple shear flow. Fig. 2 shows steady shear stress behavior of different samples, which can be used to show yield stresses of these samples. Yield stress is a certain threshold force applied to initiate flow to a system. It is related to the level of internal structure of the system which must be broken down before flow can occur (Ngee et al, 2009). The yield stress of crude oil samples was determined by plotting shear rate versus shear stress, obtained from the steady shear experiments. The intercept of shear rate vs. shear stress curve determines the yield stress (Charm, 2006). The magnitude of yield stress depends on the strength of the attractive forces holding the components together (Pal, 1997). The yield stress of crude samples is listed in Table 2. In general, the yield stress of oil samples increased with an increase in irradiation time, presenting the dissolution of aspaltenic components in crude oil. However, 40 min was assumed as the optimum irradiation time, since 40-min irradiated sample had lower yield stress which caused the oil to flow more easily. Moreover, 120- and 240-min irradiated samples with stronger attractive forces between the components due to high solubility caused by ultrasonic irradiation, had the highest yield stress values.

Table 2 Yield stress of crude oil samples after different times of ultrasonic treatment

\begin{tabular}{cc}
\hline $\begin{array}{c}\text { Ultrasonic irradiation time } \\
\text { min }\end{array}$ & $\begin{array}{c}\text { Yield stress } \\
\text { Pa }\end{array}$ \\
0 & 0.58 \\
5 & 2.19 \\
10 & 1.88 \\
20 & 1.97 \\
30 & 1.31 \\
40 & 0.93 \\
50 & 1.64 \\
90 & 1.48 \\
120 & 3.10 \\
240 & 19.39 \\
\hline
\end{tabular}

The viscosities of the crude oil samples presented in Fig. 3 decreased significantly as the applied shear rate increased, indicating shear thinning (pseudoplastic) behavior. The Kouh-e-Mond crude oil consists of heavy components such as asphaltene and wax. These components are very close to one another and thus, tend to flocculate through colloidal interactions (McClements, 1999). After a sharp reduction, there was no considerable alteration in viscosity at high shear rates. Viscosities of irradiated samples were relatively higher than non-irradiated samples due to dissolution of heavy components that were suspended in crude oil. However, as it is shown in this figure the viscosity of crude oil decreased after 30 min ultrasonic irradiation, which seems due to breakdown of asphaltene molecules to lighter molecules. After 40 min of ultrasonic irradiation (that can be considered as the optimum of irradiation time), asphaltene molecules seem to start reforming. However, the new asphaltene


Fig. 2 Shear stress changes as a function of shear rate for Iranian Kouh-e-Mondcrude oil before and after ultrasonic irradiation

molecules remain soluble in oil and increase the crude oil viscosity.

\subsection{Oscillatory analysis}

A frequency sweep is a particularly useful test as it enables the viscoelastic properties of a sample to be determined as a function of time. Several parameters can be obtained, such as the storage (elastic) modulus $\left(G^{\prime}\right)$, the viscous (loss) modulus $\left(G^{\prime \prime}\right)$, and the complex viscosity $\left(\eta^{*}\right)$. The storage modulus and loss modulus can be used as a measure of the elastic and the viscous components of the sample, respectively. To determine the linear viscoelastic behavior region, strain sweep tests were performed on different samples. Obtained results show a complete independence of dynamic rheological parameters on strain for frequency less than $15 \mathrm{~Hz}$. The plots of dynamic moduli as a function of oscillation frequency are given in Figs. 4 and 5. Both the storage $\left(G^{\prime}\right)$ and loss $\left(G^{\prime \prime}\right)$ 

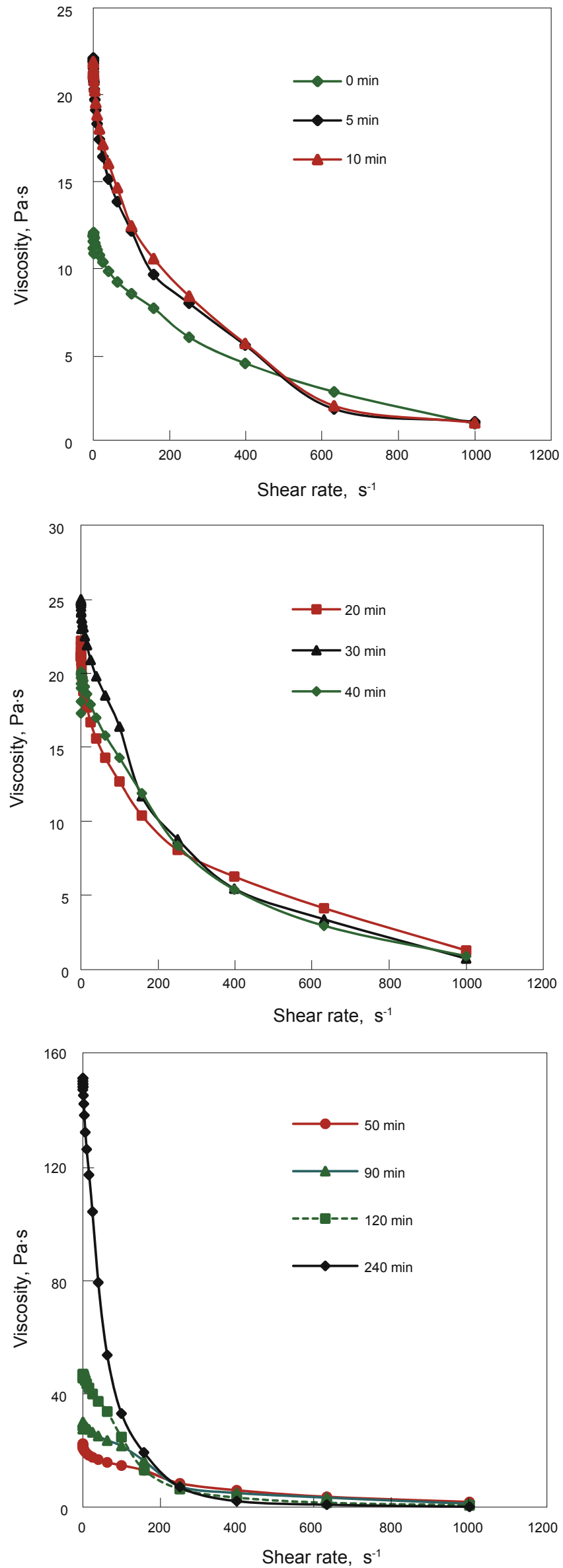

Fig. 3 Dynamic viscosity changes as a function of shear rate for Iranian Kouh-e-Mond crude oil before and after ultrasonic irradiation modulus of non-sonicated and sonicated crude oil increased with frequency of oscillation, which indicates low stability of the colloidal structure of Kouh-e-Mond crude oil. Higher $G^{\prime}$ implies that higher stresses are needed to cause the crude oil to flow (Mancini et al, 2002). It also means that colloid stability was enhanced in low stress situations therefore applying high stress to heavy oil like the Kouh-e-Mond could cause asphaltene precipitation. For all samples in measured frequencies, loss modulus values were higher than elastic ones which suggest that the liquid-like viscous property of the sample is dominant over the solid-like elastic property.
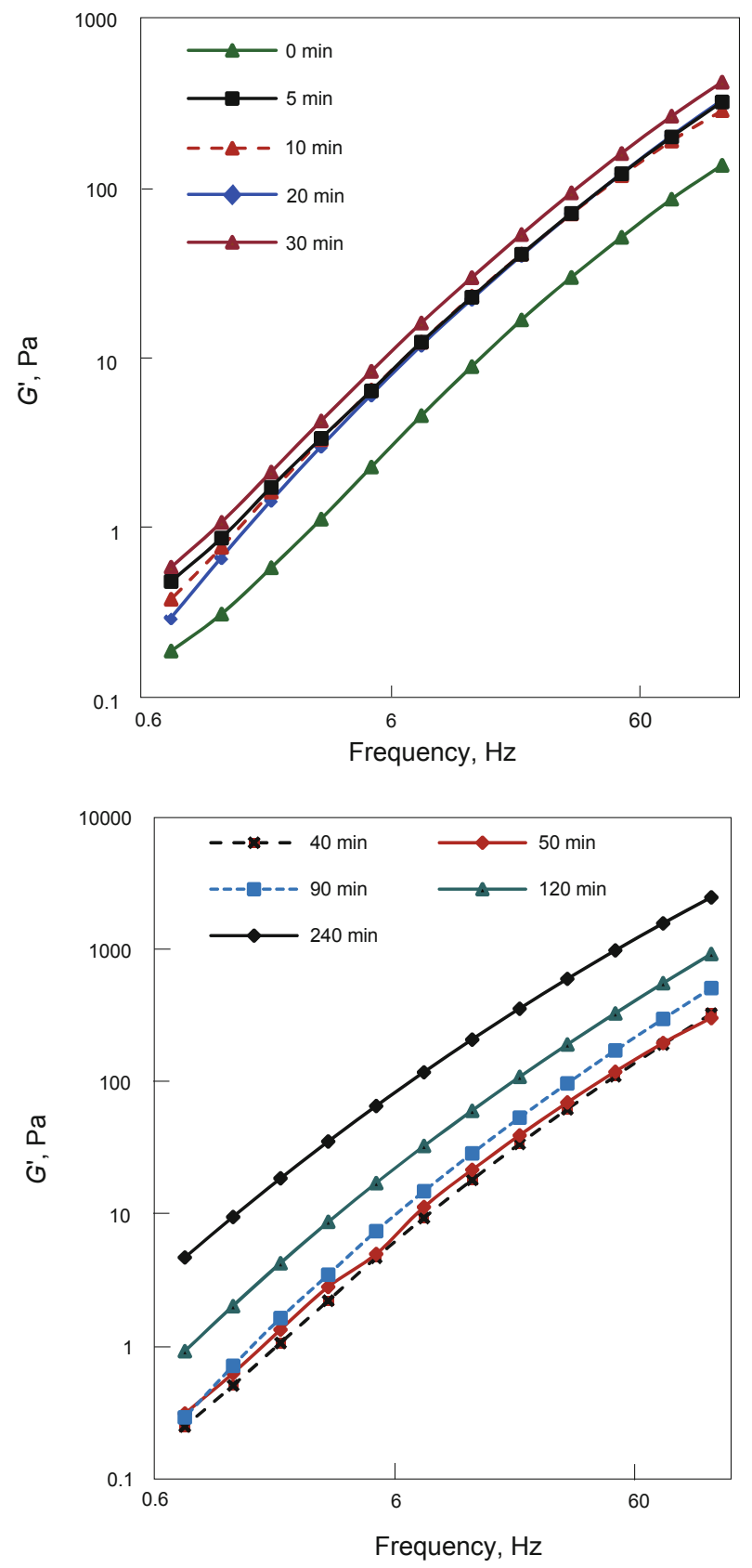

Fig. 4 Storage modulus changes as a function of frequency for Iranian Kouh-e-Mond crude oil before and after ultrasonic irradiation

Loss tangent $(\tan \delta)$ is defined as the ratio of the loss modulus to the storage modulus $\left(G^{\prime \prime} / G^{\prime}\right)$ and is dimensionless. It is a measure of the relative magnitudes of the viscous to 

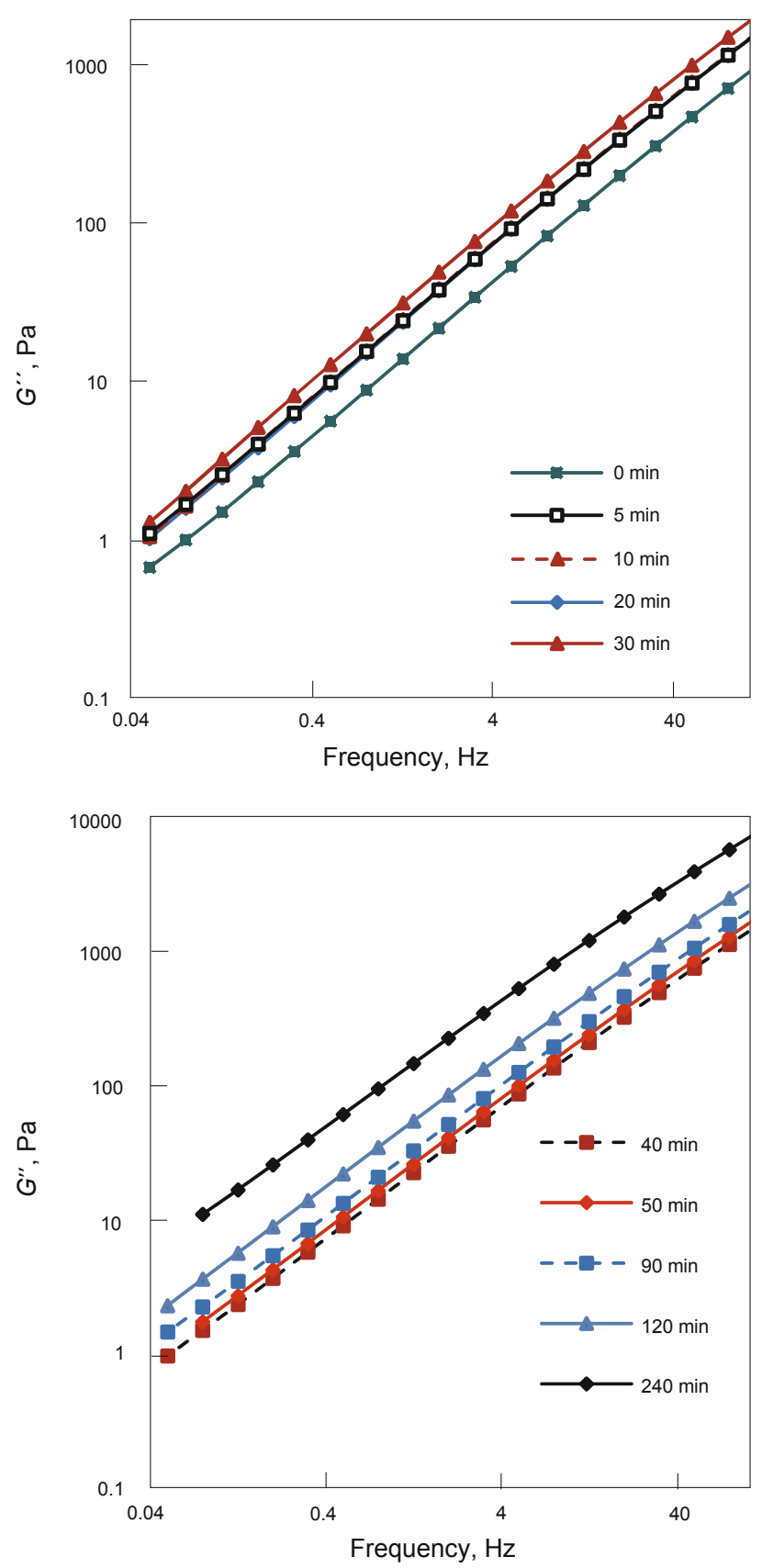

Fig. 5 Loss modulus changes as a function of frequency for Iranian Kouh-e-Mond crude oil before and after ultrasonic irradiation

elastic components. Under ultrasonic stimulation the solid components such as asphaltenes and waxes were dissolved in crude oil and the loss tangent decreased, indicating the more elastic and solid-like behavior than non-stimulated samples. Consequently, as Fig. 6 shows, applying ultrasonic waves for longer time than the optimum time can make oil production and transport more difficult.

\subsection{Confocal microscopy}

Fig. 7 shows confocal images of non-irradiated and irradiated samples after 120 minutes of flocculation with $60 \% n$-pentane. It could be observed that the size of the flocs of asphaltenes in sonicated samples was smaller than that in non-sonicated samples. The flocculation of asphaltene
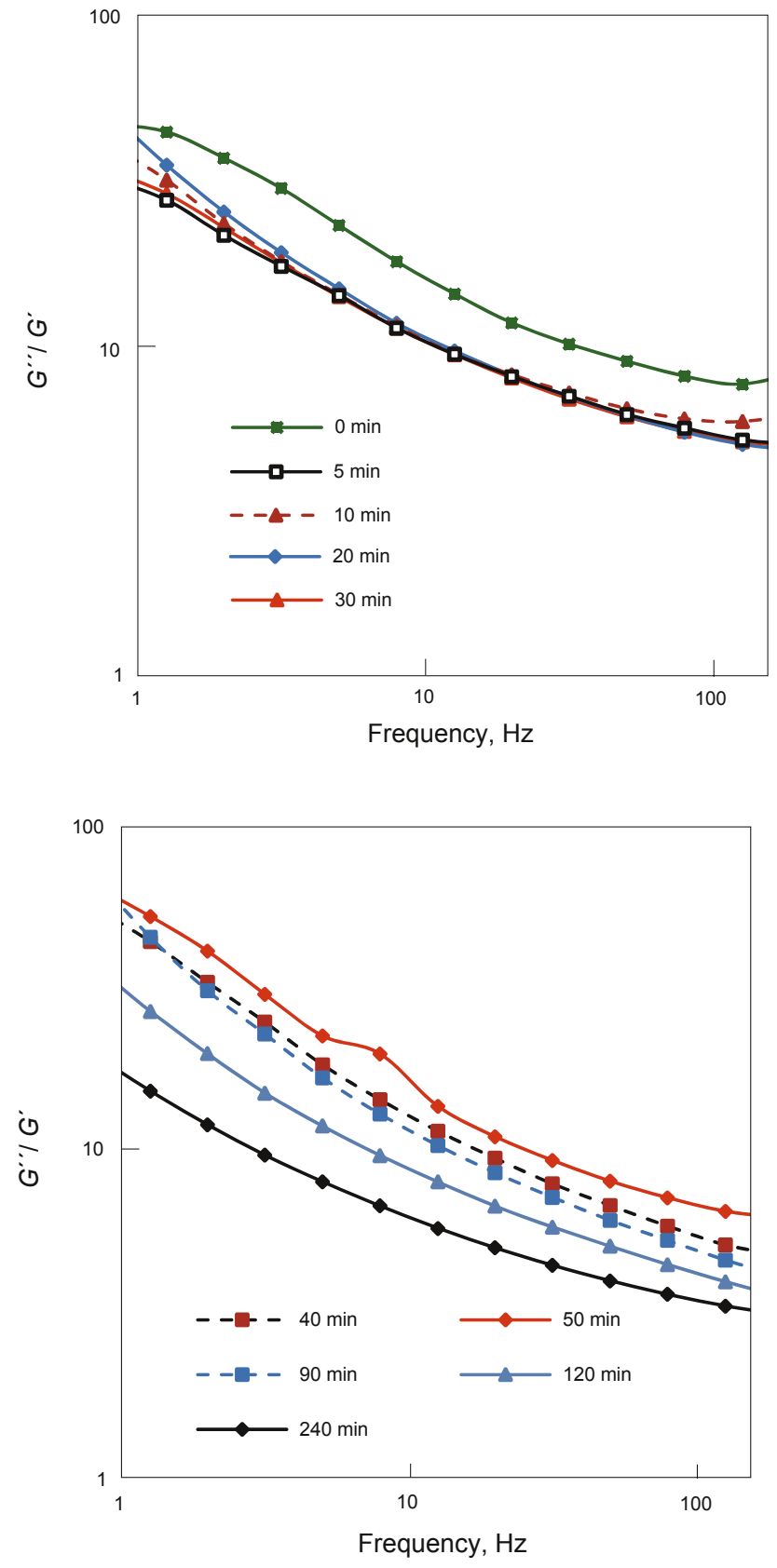

Fig. 6 Loss tangent changes as a function of frequency for Iranian Kouh-e-Mond crude oil before and after ultrasonic irradiation

particles were the same at different times of aggregation for each sample. Fig. 7 (a) shows a huge fractal structure whose size is near $10 \mu \mathrm{m}$ for the non-sonicated sample. The average radius of asphaltene particles in this sample was $3.7 \mu \mathrm{m}$. For 20-min irradiated sample (Fig. 7(b)), the average radius of flocs decreased to $3.4 \mu \mathrm{m}$ and the particle size ranged from 1 to $17 \mu \mathrm{m}$. It seems that ultrasonic irradiation could reduce the average radius of flocs, in addition to preventing the formation of particles with a huge size. The reduction continued for the 40-min irradiated sample (Fig. 7(c)), the average radius of aggregates was $2 \mu \mathrm{m}$.

\subsection{Size distribution of asphaltene aggregates}

Fig. 8 shows the size distribution curves obtained 




(a) Non-irradiated crude oil

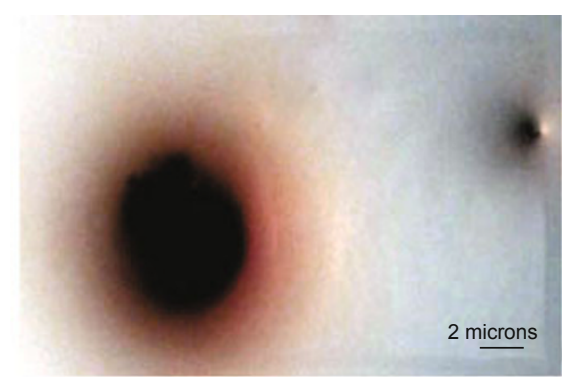

(b) 20-min irradiated crude oil



(c) 40-min irradiated crude oil

Fig. 7 Confocal images of Kouh-e-Mond crude oil after 120 min of flocculation with $60 \% n$-pentane

after $120 \mathrm{~min}$ of flocculation of Kouh-e-Mond crude oil samples. Fig. 8 (a) demonstrates that the asphaltene particles distributed in the non-irradiated sample with a maximum size of around $2.5 \mu \mathrm{m}$. In the $20-\mathrm{min}$ irradiated sample, the size of solid particles was mainly in the range of 1 to $17 \mu \mathrm{m}$ and only $2.8 \%$ of all aggregate particles had a size more than 12 $\mu \mathrm{m}$. This indicates that ultrasonic irradiation could reduce the possibility of formation of macro structure aggregates. After 40 min of irradiation, the small flocs of asphaltene particles formed had a narrower size distribution, implying breakdown of asphaltene molecules. Since the asphaltene deposits can plug pore holes, they have serious effect on the rock permeability and ultrasonic treatment may help solving this problem.

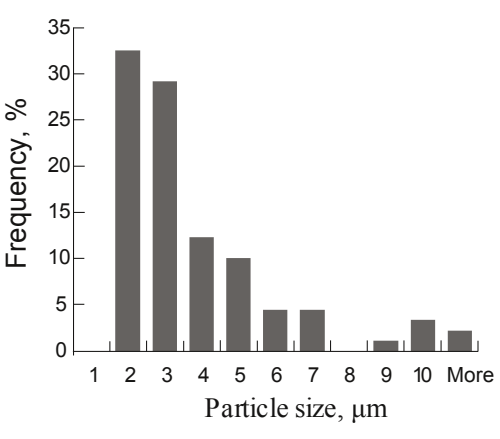

(a) Non-irradiated crude oil

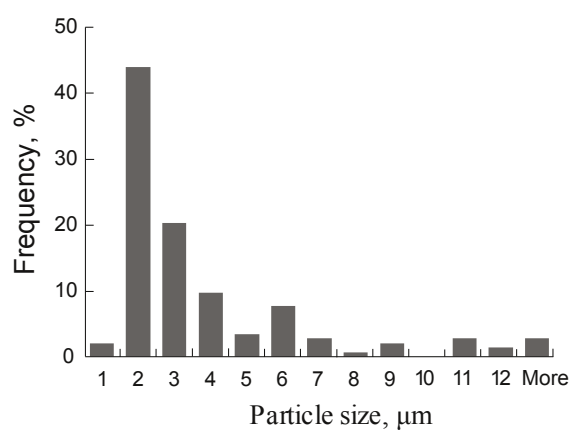

(b) 20-min irradiated crude oil

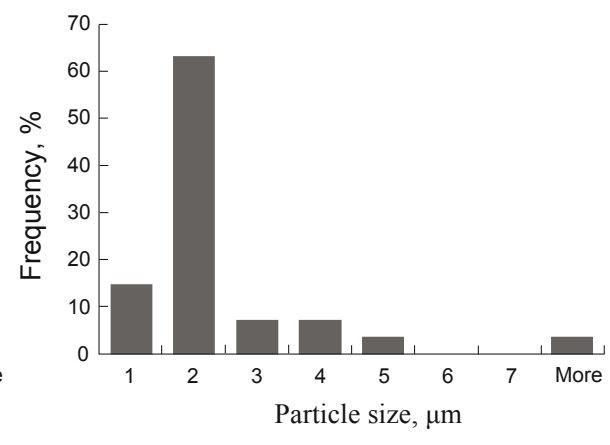

(c) 40-min irradiated crude oil

Fig. 8 Particle size distribution of Kouh-e-Mond crude oil after $120 \mathrm{~min}$ of flocculation with $60 \% n$-pentane

\subsection{Temperature sweep test}

Fig. 9 demonstrates the viscosity of non-sonicated crude oil samples as a function of temperature. The Kouh-e-Mond reservoir temperature is $55^{\circ} \mathrm{C}$ and the test was run over a temperature range from $30-161{ }^{\circ} \mathrm{C}$. Heating can dissolve

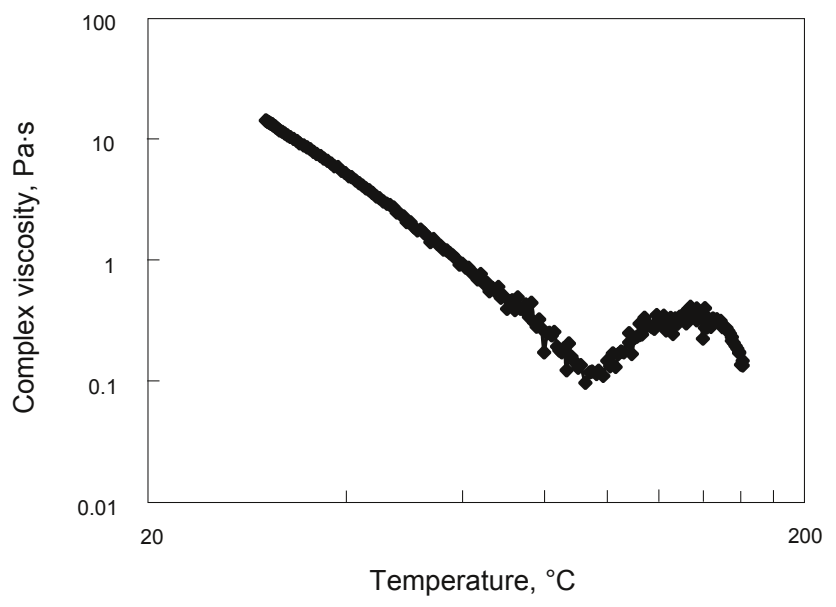

Fig. 9 Viscosity changes as a function of temperature at a constant frequency of $10 \mathrm{~Hz}$ for Iranian Kouh-e-Mond crude oil and break the asphaltene molecules (Rønningsen, 2004; Garshol, 2005). At about $100{ }^{\circ} \mathrm{C}$ asphaltene molecules began to dissolve in oil and the oil viscosity increased. After $150{ }^{\circ} \mathrm{C}$ the temperature effect would be dominant over asphaltene flocs breaking and the oil viscosity reduced again. The heat produced by ultrasound elevated the oil temperature, but regarding the radiation setup used in this study, the temperature increment was not more than $30^{\circ} \mathrm{C}$ for a long time of ultrasonic irradiation. Therefore, the rheological changes that ultrasonic treatment induced in crude oil cannot be the result of the minor temperature increase caused by ultrasound.

\section{Conclusions}

Steady and dynamical rheological measurements in addition to confocal microscopy tests were conducted to investigate the effect of ultrasonic irradiation on flow behavior of heavy crude oil taken from the Kouh-e-Mond Oil Field. The following conclusions could be drawn.

1) Overall, ultrasonic irradiation could increase the value of stress required for flow of crude oil samples (yield stress). However, an irradiation time was found in which the yield stress is the minimum and ease of flow is the highest. 
2) According to the results of frequency sweep tests, applying ultrasonic waves for a long time (more than the optimum time) decreases the loss tangent which implies more elastic and solid-like behavior of crude oil and would make oil production and transport more difficult.

3 ) Ultrasound could reduce generation of macrostructure flocs. This would remarkably reduce negative effects of asphaltene deposition on the absolute and relative permeability of reservoir rocks.

4) Temperature sweep tests indicate that the temperature increment due to ultrasonic irradiation was not the reason for breakdown of asphaltene molecules and other physical and chemical changes. These alterations were highly related to the wave energy, itself.

5) According to the tests performed in this study there was an optimum duration for ultrasonic irradiation to reduce the viscosity, yield stress and size of flocs in asphaltenic crude oils to their minimum values which should be considered as a requirement in ultrasonic technology designing. This value was found to be about $40 \mathrm{~min}$ for Kouh-e-Mond crude oil.

\section{References}

Argillier J-F, Barré L, Brucy F, et al. Influence of asphaltenes content and dilution on heavy oil rheology. Paper SPE 69711 presented at SPE International Thermal Operations and Heavy Oil Symposium held in Porlamar, Margarita Island, Venezuela, 12-14 March, 2001

Azin R, Kharrat R, Vossoughi S, et al. Study of the VAPEX process in fractured physical systems using different solvent mixtures. Oil \& Gas Science and Technology- Rev. IFP. 2008. 63: 219-227

Charm S E. The direct determination of shear stress-shear rate behavior of foods in the presence of a yield stress. Journal of Food Science.
2006. 28: 107-113

Garshol T A. Investigation of asphaltene precipitation mechanisms on the Gyda Field: Literature and case study. Ph.D. Dissertation. Norwegian University of Science and Technology. 2005

Kamath V A, Yang J and Sharma G D. Effect of asphaltene deposition on dynamic displacement by water. Paper SPE 26046 presented at SPE Western Regional Meeting, Anchorage, Alaska, 26-28 May, 1993

Manan M A, Mat H B and Ming L J. Rheological properties of crude oil emulsion. Regional Symposium on Chemical Engineering in conjunction with 13th Symposium of Malaysian Chemical Engineers. Hyatt Regency, Johor, Malaysia, 13-15 October, 1997

Mancini F, Montanari L, Peressini D, et al. Influence of alginate concentration and molecular weight of functional properties of mayonnaise. Lebensm. Wiss. Technol. 2002. 35: 517-525

McClements D J. Food Emulsions: Principles, Practice and Techniques. CRC Press. Boca Raton, FL, 1999

Minssieux L. Core damage from crude asphaltene deposition. Paper SPE 37250 presented at International Symposium on Oilfield Chemistry, Houston, Texas, 18-21 February, 1997

Mousavi S M, Najafi I, Ghazanfari M, et al. Quantitative analysis of ultrasonic wave radiation on reversibility and kinetics of asphaltene flocculation. EAGE International Conference and Exhibition on Geosciences, Saint Petersburg, 5-8 March, 2010

Ngee L H, Kassim A, Ming H N, et al. Study of highly concentrated olive oil-in-water emulsions stabilized by palm-based nonionic surfactant. Sains Malaysiana. 2009. 38: 95-102

Pal R. Viscosity and storage/loss moduli for mixtures of fine and coarse emulsion. Chemical Engineering Journal. 1997. 67: 37-44

Pedroza T and Calderon G. Impact of asphaltene presence on some rock properties. SPE Advanced Technology Series. 1995. 4(1): 185-191

Rønningsen H P. Transport of waxy crudes in multiphase flowlines. Presented at NTNU, Trondheim 11 April, 2004

(Edited by Sun Yanhua) 